O OPEN ACCESS

phytobiomesjournal.org

\title{
More than Serendipity: The Potential to Manage Soil Carbon and Emissions While Promoting Low-Input Agriculture with Serendipitoid Mycorrhizae
}

\author{
Kelly D. Craven ${ }^{\dagger}$ and Prasun Ray \\ Noble Research Institute, LLC, Ardmore, OK 73401 \\ Accepted for publication 29 May 2019.
}

\section{ABSTRACT}

Organic matter (OM) has a tremendous influence on the biological, chemical, and physical properties of soils, making it a vital component of healthy agricultural systems. Release of the nutrients locked within soil OM requires the activity of soil microorganisms, primarily decomposers, to transform it into nutritive forms that can be used by other microbes and plants. OM turnover is a good thing, as it liberates the locked up nutrients. However, when this liberation is accomplished by freeliving decomposer communities, i.e., those not typically forming relationships with plants, the carbon may be used mostly to form microbial biomass and the rest respired as $\mathrm{CO}_{2}$, thereby aggravating greenhouse gas emission. Serendipitoid fungi (e.g., Serendipita spp.) are soil-dwelling basidiomycetes, known for decades to form mycorrhizal associations with wide variety of plant species. We hypothesize that serendipitoid fungi are capable of decomposing OM in a manner akin to free-living decomposer communities. However, serendipitoid fungi are capable of colonizing the root systems of plant community members, potentially restricting access to nutritional stores in the soil, thus imparting efficiency to the system and limiting unnecessary losses. From our perspective, this is a more rational, resilient, and ultimately more sustainable strategy than the annual addition of inorganic forms of micro- and macronutrients. Using microbes like Serendipita spp. in this manner could ultimately make the system less susceptible to nutritional fluxes that may influence productivity and stress tolerance in our crop plants.

Keywords: endophytes, microbiome, mycology, nutrient cycling, organic amendments, symbiosis
Organic matter (OM) has a tremendous influence on the biological, chemical, and physical properties of soils, making it a vital component of healthy agricultural systems. Immediate benefits are that OM holds water and improves soil aeration, while there are also accrued benefits wherein $\mathrm{OM}$ is seen as both a means of sequestering $\mathrm{C}$ in the soil and of storing nutrients for future crop use. Many studies have linked plant productivity to soil OM (SOM) content (Bauer and Black 1994; Seremesic et al. 2011) and many natural ecosystems depend heavily upon decomposition of SOM as a means of macro- and micronutrient release (Lehmann and Kleber 2015; Marschner and Kalbitz 2003). The importance of SOM in

${ }^{\dagger}$ Corresponding author: K. D. Craven; kdcraven@noble.org

Funding: This work was supported by the Center for Bioenergy Innovation project. The Center for Bioenergy Innovation is a United States Department of Energy (DOE), Office of Science Bioenergy Research Center supported by the Office of Biological and Environmental Research (OBER) in the DOE Office of Science.

The author(s) declare no conflict of interest.

(C) 2019 The American Phytopathological Society agricultural soils cannot be over emphasized, affecting the biological, chemical, and physical nature of this vital resource. Subsequently, cropping systems that employ ecologically sound management strategies, such as no-till and cover cropping are aimed at increasing the total SOM content.

Every part of plants grown in living soil is associated with various microorganisms including bacteria, fungi, oomycetes, nematodes, protozoa, algae, viruses, archaea, and arthropods. The microbial composition is more abundant and complex in the rhizosphere, the narrow zone surrounding the plant roots, with $10^{9}$ cells per gram in typical rhizospheric soil, comprising up to $10^{6}$ taxa (Lakshmanan et al. 2017). Release of the nutrients locked within SOM requires these microorganisms, primarily decomposers, to secrete organic acids and enzymes that can loosen and break down the cellulose and recalcitrant lignin into nutritive forms that can be used by other microbes and plants (Campbell et al. 1991; Fontaine et al. 2003). However, the actual release of this nutrition is accomplished primarily through microbial decomposition, and is accompanied by the respiration of $\mathrm{C}$ as gaseous $\mathrm{CO}_{2}$ during its degradation. In our opinion, low abundance of organic residues in agricultural soils arises at least partly due to an inability to exert more control over the 
decomposition process, both in terms of its rate, and its efficiency of transfer. If we could more precisely control the turnover time and dynamics of SOM decomposition in agricultural soils, we could potentially reap the benefits of both extended nutrient release over time and mitigate GHG emission due to agriculture.

While the macro- and micronutrients locked up in OM are ultimately made available to all members of the phytobiome, it is commonly understood that the $\mathrm{C}$ is primarily monopolized by the microbes (Schimel and Schaeffer 2012), with the plants capable of obtaining their own $\mathrm{C}$ through photosynthesis. An exception is evident in myco-heterotrophy, where plants obtain all or part of their $\mathrm{C}$ from mycorrhizal or free-living fungi, sometimes only for germination while others remain "parasitic" on the fungus for their entire life cycle. This relationship is common in orchids, which lack any endosperm in their seed, and require their mycorrhizal symbiont to provide nutrients and $\mathrm{C}$ for seed germination (Rasmussen and Rasmussen 2009).

OM turnover is generally considered a good thing, as it liberates the nutrients locked up within. However, when this liberation is accomplished by "free-living" decomposer communities, i.e., those not typically forming relationships with plants, the $\mathrm{C}$ may be used mostly to form microbial biomass and the rest respired as $\mathrm{CO}_{2}$. Certain agronomic practices contribute significantly to soil respiration; particularly tilling that turns the soil to promote OM degradation. This greatly stimulates microbial decomposer activity, leading to $\mathrm{OM}$ breakdown and huge respiratory bursts of $\mathrm{CO}_{2}$. Across major world biomes, a direct relationship between soil respiration and net primary production, with an $r^{2}=0.87$ has been shown (Raich and Schlesinger 1992). Partly for this reason, farmers have traditionally used tilling to stimulate the decomposition process, turning their soils and exposing $\mathrm{OM}$ and crop residues to free-living decomposer communities in competitive, "open" systems. While a portion of phosphorous and $\mathrm{N}$ released in this process is made available for reuptake by the next crop, there are significant $\mathrm{C}$ losses in the form of dissolved organic carbon and huge bursts of microbial $\mathrm{CO}_{2}$ respiration. Other microbes emit nitrous oxide, another potent greenhouse gas, as a by-product of their metabolism thus causing losses of $\mathrm{N}$ to the system. Most ecosystem models predict that climate warming will stimulate microbial decomposition of soil $\mathrm{C}$, producing a positive feedback to rising global temperatures (Friedlingstein et al. 2006; Lloyd and Taylor 1994), and such microbial decomposition of soil $\mathrm{C}$ in response to climate warming depends on the efficiency of soil microbes in using C (Allison et al. 2010).

Unfortunately, this type of indirect nutrient transfer, inherent in a free-living decomposition system, can be unpredictable and inefficient. Nutrition made available to the plants in some sense can even be viewed as a fortuitous by-product of microbial respiration and metabolism. Even if all of the nutrition locked up in microbial biomass is ultimately released to the plants as it decomposes (referred to as necromass), the process is highly inefficient and losses to the system are likely to be substantial. Perhaps most importantly, it is likely only a fraction of what the plants could potentially gain through a more predictable, directed decomposition process. From an evolutionary perspective, the fitness of the decomposer community may be uncoupled to that of the agricultural plant community. While this may be an acceptable outcome or even advantageous in certain natural ecosystems, in agricultural ones it imparts unpredictability and reduces the impact of nutrition from OM pools on plant performance. Open OM decomposition may reduce the nutritional return after which we are forced to supplement that portion with pulses of inorganic fertilizer that overwhelm the plant's ability to take them up, leaching into the world's waterways and often resulting in environmental damage. Seasonal additions at the local scale may even suppress the formation of a longer term, resilient phytobiome, including beneficial symbioses forged between plants and the microbes that share air, water, and soil. This results in plant-microbe communities dependent upon external additions and collectively susceptible to environmental perturbations.

Evidence that the turnover of $\mathrm{OM}$ is generally positive for plant productivity also comes from instances where it is retarded such as in the formation of bogs and heathlands, where a lack of decomposer activity is associated with an increasing accumulation of $\mathrm{OM}$ and a nutritional depletion and acidification of the soil. These factors can potentially feed on one another in a vicious cycle, until plant productivity is severely reduced and confined to members of acid-tolerant, low nutritional quality plant families like Ericaceae (Eskelinen et al. 2009). Here, the mycorrhizal associates of ericoid plants have been documented to actually out-compete their decomposer kinsman through their linkage to an autonomous, photosynthesizing host plant. In soils where $\mathrm{N}$ and $\mathrm{P}$ become severely limiting, free-living decomposers are at a major disadvantage to their mycorrhizal cousins because they cannot access the $\mathrm{C}, \mathrm{N}$, and $\mathrm{P}$ that they need to produce biomass and thus are incapable of any substantial organic acid and enzyme secretion needed to further mobilize the nutrients locked up in the abundant OM. In contrast, the mycorrhizae has access to photosynthetically derived $\mathrm{C}$ from its plant host, which it can use to fuel organic acid and enzyme production, thus giving it a monopoly on the $\mathrm{OM}$ and the nutrition locked inside. It repays the host plant for this symbiotic service by funneling $\mathrm{N}$ and $\mathrm{P}$ (and sometimes $\mathrm{C}$ too) back to its host through its mycelium that expands in the absence of any real competition. This is in large part why ericaceous plants often dominate in the heathland ecosystems they inhabit.

The use of organisms to offset nutrient and water inputs has a long, rather checkered history, but more recently, next-generation sequencing has revolutionized our understanding of microbial community composition and function, and together with improved culturing methodologies has greatly facilitated the use of biologicals in the field (Mueller and Sachs 2015; Panke-Buisse et al. 2014; Schweitzer et al. 2008). One group of microbes that has emerged from obscurity through such analyses is the serendipitoid fungi (kingdom Fungi, phylum Basidiomycota, family Serendipitaceae). Intriguingly, in many natural ecosystems these fungi form mycorrhizal symbioses with an astounding variety of host plants. Genotypes of the fungus have been detected and classified (largely based on host association and structures formed in planta) as either ecto-, endo-, orchid, ericoid, or jungermannioid mycorrhizae (Selosse et al. 2007; Weiß et al. 2011). Just as striking, the few strains that have been successfully isolated in culture appear to be phenotypically plastic and capable of forming multiple mycorrhizal types.

Serendipitoid fungi are soil-dwelling basidiomycetes, known to form mycorrhizal associations with orchids and ericaceous plants. Unlike arbuscular mycorrhizae, which exchange inorganic, mineralized nutrients mined from the soil for $\mathrm{C}$ derived from host photosynthesis, serendipitoid mycorrhizae have a complete arsenal of carbohydrate-active enzymes (CAZymes) that likely endows them with saprotrophic abilities. Therefore, we hypothesize that serendipitoid mycorrhizae can access nutrients locked up in OM, such as crop residues. Not only would this give these fungi access to an additional nutrient pool, but the $\mathrm{C}$ liberated in the process may be used to reduce the amount required by the serendipitoid mycorrhiza from the plant host.

From this perspective, the genome sequence of the fungal symbiont, Serendipita vermifera subsp. bescii, published in a recent issue of Phytobiomes Journal (Ray et al. 2018), is particularly 
significant. Isolated from the root system of switchgrass (Panicum virgatum L.), a warm-season prairie grass, this fungus associates with plants as an endomycorrhizae. Previous work has demonstrated that significant improvements in yield and stress tolerance of multiple crops such as switchgrass ( $P$. virgatum), wheat (Triticum aestivum L.), and alfalfa (Medicago sativa L.) (Craven and Ray 2017; Ray and Craven 2016; Ray et al. 2015) can be gained through symbiosis with this single fungal strain. In addition to its role in plant symbiosis, the genome of $S$. bescii contains a large number of genes encoding CAZymes, or carbohydrate-active enzymes. Representing approximately $3 \%$ of the entire gene set, S. bescii has a CAZymes complement rivaling more well-known wood rotters, and much more than other symbiotic fungi such as ectomycorrhizae or grass-infecting epichloae endophytes (Weiß et al. 2016). The large majority of these fungi belong to the Basidiomycota, a diverse group containing most of the decomposer fungi, i.e., white, brown, and soft rotters. The fascinating attribute that separates these Basidiomycota from the serendipitoid fungi like $S$. bescii is that, the latter seem to maintain a largely symbiotic lifestyle with the roots of living host plants, whereas their related rotters maintain a solitary, free-living lifestyle, seeking only dead or dying plant tissues as their source of subsistence. Based upon recent genomics and proteomics data (Ray et al. 2019), as well as emerging insights into the associations they forge with plants in natural habitats, we hypothesize

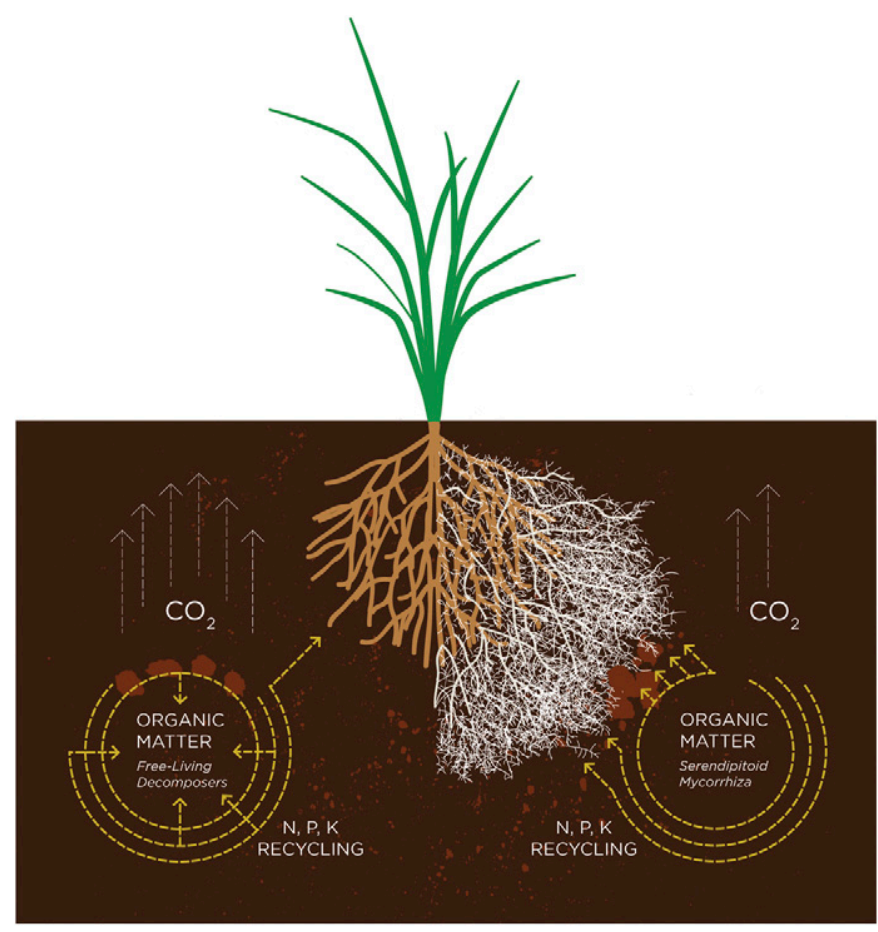

Fig. 1. A cropping system that could limit $C, N$, and $P$ losses while simultaneously reaping the benefits of symbiotic nutritional capture and transport would greatly facilitate sustainable, low-input agriculture. We propose to utilize a "tight-loop" decomposition system based upon the incorporation of a serendipitoid symbiont into the cropping system. Serendipitoid mycorrhiza seem to maintain a largely symbiotic lifestyle with the roots of living host plants, whereas the related brown and white rot fungi maintain a largely solitary, free-living lifestyle, seeking only dead or dying plant tissues as their source of subsistence. Serendipitoid mycorrhiza are capable of decomposing organic matter in a manner akin to free-living decomposer communities. Additionally, they symbiotically colonize the plants, which may restrict access to nutritional stores in the soil, thus making the system less susceptible to nutritional fluxes and limiting unnecessary losses. that these serendipitoid fungi are capable of decomposing OM in a manner akin to free-living decomposer communities. However, instead of the uncoupled and inefficient means of OM nutrient extraction that operate in open decomposition systems (Fig. 1, left side), serendipitoid fungi symbiotically colonize the root systems of plant community members, thereby restricting access to nutritional stores in the soil, and limiting unnecessary losses (Fig. 1, right side).

A cropping system that could limit $\mathrm{C}, \mathrm{N}$, and $\mathrm{P}$ losses while simultaneously reaping the benefits of symbiotic nutritional capture and transport would greatly facilitate sustainable, low-input agriculture. We suggest that a tight-loop decomposition system based on serendipitoid symbionts in cropping systems could be developed (Fig. 1). This novel type of plant-associated fungus pairs the recycling capabilities of a decomposer with a symbiotic growth habit and very desirable plant growth-promoting properties. We have shown that these fungi capable of cultivation can be inoculated onto, and improve biomass and stress tolerance of an enormous spectrum of agronomically important crop plants (Ghimire et al. 2009; Ray and Craven 2016). From our perspective, we propose this could be a more rational, resilient, and ultimately more sustainable strategy than the annual addition of inorganic forms of micro- and macronutrients. Restricting access in this manner will ultimately make the system less susceptible to nutritional perturbations that impact productivity and stress tolerance in crop plants. We are currently evaluating $\mathrm{C}$ fluxes in plants with root systems colonized by serendipitoid fungi. Should our conceptual model be correct, we will have demonstrated not only the effective engineering of a more predictable and productive phytobiome, but a biological strategy to impart greater control over both the quantities of nutrients and $\mathrm{C}$ in our agricultural soils as well as their flux into and out of the system.

\section{ACKNOWLEDGMENTS}

We thank J. Meo from Noble Research Institute for graphic design.

\section{LITERATURE CITED}

Allison, S. D., Wallenstein, M. D., and Bradford, M. A. 2010. Soil-carbon response to warming dependent on microbial physiology. Nat. Geosci. 3: 336-340.

Bauer, A., and Black, A. 1994. Quantification of the effect of soil organic matter content on soil productivity. Soil Sci. Soc. Am. J. 58:185-193.

Campbell, C., Lafond, G., Zentner, R., and Biederbeck, V. 1991. Influence of fertilizer and straw baling on soil organic matter in a thin Black Chernozem in western Canada. Soil Biol. Biochem. 23:443-446.

Craven, K., and Ray, P. 2017. Symbiont for enhancement of plant performance. U.S. Patent Appl. 15/626,926.

Eskelinen, A., Stark, S., and Männistö, M. 2009. Links between plant community composition, soil organic matter quality and microbial communities in contrasting tundra habitats. Oecologia 161:113-123.

Fontaine, S., Mariotti, A., and Abbadie, L. 2003. The priming effect of organic matter: A question of microbial competition? Soil Biol. Biochem. 35: 837-843.

Friedlingstein, P., Cox, P., Betts, R., Bopp, L., von Bloh, W., Brovkin, V., Cadule, P., Doney, S., Eby, M., and Fung, I. 2006. Climate-carbon cycle feedback analysis: Results from the C4MIP model intercomparison. J. Clim. 19:3337-3353.

Ghimire, S. R., Charlton, N. D., and Craven, K. D. 2009. The mycorrhizal fungus, Sebacina vermifera, enhances seed germination and biomass production in switchgrass (Panicum virgatum L.). BioEnergy Res. 2:51-58.

Lakshmanan, V., Ray, P., and Craven, K. D. 2017. Toward a resilient, functional microbiome: Drought tolerance-alleviating microbes for sustainable agriculture. Pages 69-84 in: Plant Stress Tolerance. Springer.

Lehmann, J., and Kleber, M. 2015. The contentious nature of soil organic matter. Nature 528:60-68. 
Lloyd, J., and Taylor, J. 1994. On the temperature dependence of soil respiration. Funct. Ecol. 8:315-323.

Marschner, B., and Kalbitz, K. 2003. Controls of bioavailability and biodegradability of dissolved organic matter in soils. Geoderma 113:211-235.

Mueller, U. G., and Sachs, J. L. 2015. Engineering microbiomes to improve plant and animal health. Trends Microbiol. 23:606-617.

Panke-Buisse, K., Poole, A. C., Goodrich, J. K., Ley, R. E., and Kao-Kniffin, J. 2014. Selection on soil microbiomes reveals reproducible impacts on plant function. ISME J. 9:980-989.

Raich, J. W., and Schlesinger, W. H. 1992. The global carbon dioxide flux in soil respiration and its relationship to vegetation and climate. Tellus B 44:81-99.

Rasmussen, H. N., and Rasmussen, F. N. 2009. Orchid mycorrhiza: Implications of a mycophagous life style. Oikos 118:334-345.

Ray, P., Abraham, P. E., Guo, Y., Giannone, R. J., Engle, N. L., Yang, Z. K., Jacobson, D., Hettich, R. L., Tschaplinski, T. J., and Craven, K. D. 2019. Scavenging organic nitrogen and remodeling lipid metabolism are key survival strategies adopted by the endophytic fungi, Serendipita vermifera and Serendipita bescii to alleviate nitrogen and phosphorous starvation in vitro. Environ. Microbiol. Rep. .

Ray, P., Chi, M.-H., Guo, Y., Chen, C., Adam, C., Kuo, A., LaButti, K., Lipzen, A., Barry, K. W., Grigoriev, I. V., Tang, Y., and Craven, K. D. 2018. Genome sequence of the plant growth promoting fungus Serendipita vermifera subsp. bescii: The first native strain from North America. Phytobiomes J. 2:62-63.
Ray, P., and Craven, K. D. 2016. Sebacina vermifera: A unique root symbiont with vast agronomic potential. World J. Microbiol. Biotechnol. 32:16.

Ray, P., Ishiga, T., Decker, S. R., Turner, G. B., and Craven, K. D. 2015. A novel delivery system for the root symbiotic fungus, Sebacina vermifera, and consequent biomass enhancement of low lignin COMT switchgrass lines. BioEnergy Res. 8:922-933.

Schimel, J., and Schaeffer, S. 2012. Microbial control over carbon cycling in soil. Front. Microbiol. 3:348.

Schweitzer, J. A., Bailey, J. K., Fischer, D. G., LeRoy, C. J., Lonsdorf, E. V., Whitham, T. G., and Hart, S. C. 2008. Plant-soil-microorganism interactions: Heritable relationship between plant genotype and associated soil microorganisms. Ecology 89:773-781.

Selosse, M. A., Setaro, S., Glatard, F., Richard, F., Urcelay, C., and Weiß, M. 2007. Sebacinales are common mycorrhizal associates of Ericaceae. New Phytol. 174:864-878.

Seremesic, S., Milosev, D., Djalovic, I., Zeremski, T., and Ninkov, J. 2011. Management of soil organic carbon in maintaining soil productivity and yield stability of winter wheat. Plant Soil Environ. 57:216-221.

Weiß, M., Sykorova, Z., Garnica, S., Riess, K., Martos, F., Krause, C., Oberwinkler, F., Bauer, R., and Redecker, D. 2011. Sebacinales everywhere: Previously overlooked ubiquitous fungal endophytes. PLoS One 6:e16793.

Weiß, M., Waller, F., Zuccaro, A., and Selosse, M. A. 2016. Sebacinales-one thousand and one interactions with land plants. New Phytol. 211:20-40. 